\title{
Laser Desorption Ionization Mass Spectrometry Imaging of Drosophila Brain using Matrix Sublimation versus Modification with Nanoparticles
}

\author{
Nhu T. N. Phan, $\uparrow, \ddagger$ Amir S. Mohammadi,,,$\S$ Masoumeh D. Pour, $\$, \S$ and Andrew G. Ewing*, $, \uparrow, \S$ \\ $\uparrow$ Department of Chemistry and Molecular Biology, University of Gothenburg, Kemivägen 10, SE-412 96 Gothenburg, \\ Sweden
}

„National Center Imaging Mass Spectrometry, Kemivägen 10, SE-412 96 Gothenburg, Sweden

$\S$ Department of Chemical and Biological Engineering, Chalmers University of Technology, Kemivägen 10, SE-412 96

Gothenburg, Sweden

In this Supporting Information, we present figures demonstrating SEM images of distribution of gold NPs on a sample surface and on the surface of the fly brain, interferences of sample embedding materials on fly brain spectra, spectral interferences of DHB and CHCA at mass range below 400 Da, standard lipid DLPC and DOPC analyzed with matrixes DHB and CHCA, standard lipids on the fly brain analyzed using AuNP modification, spectra comparing MALDI and SALDI performances for fly brains obtained from different sample preparation methods, and list of enhanced peaks due to the use of TFA treatment after DHB sublimation.

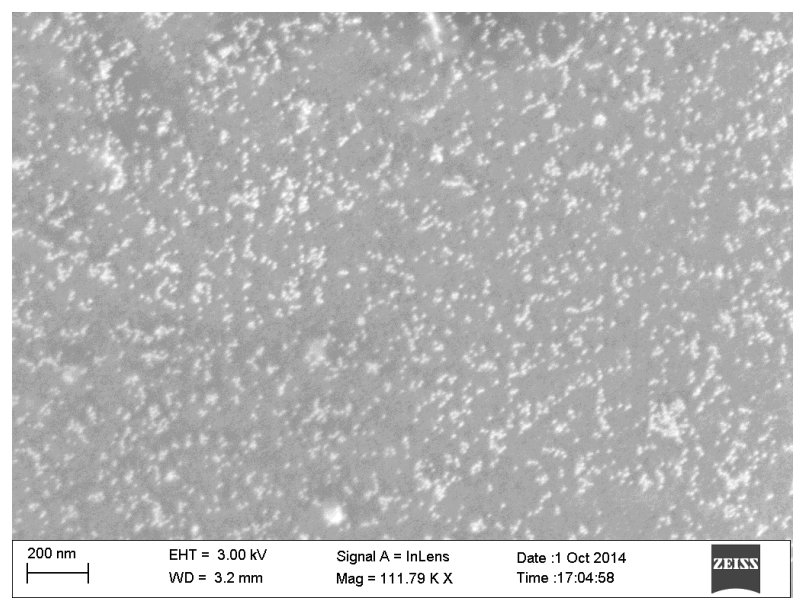

S1. SEM image of the distribution of gold NPs on a sample surface shows little or no aggregation. 

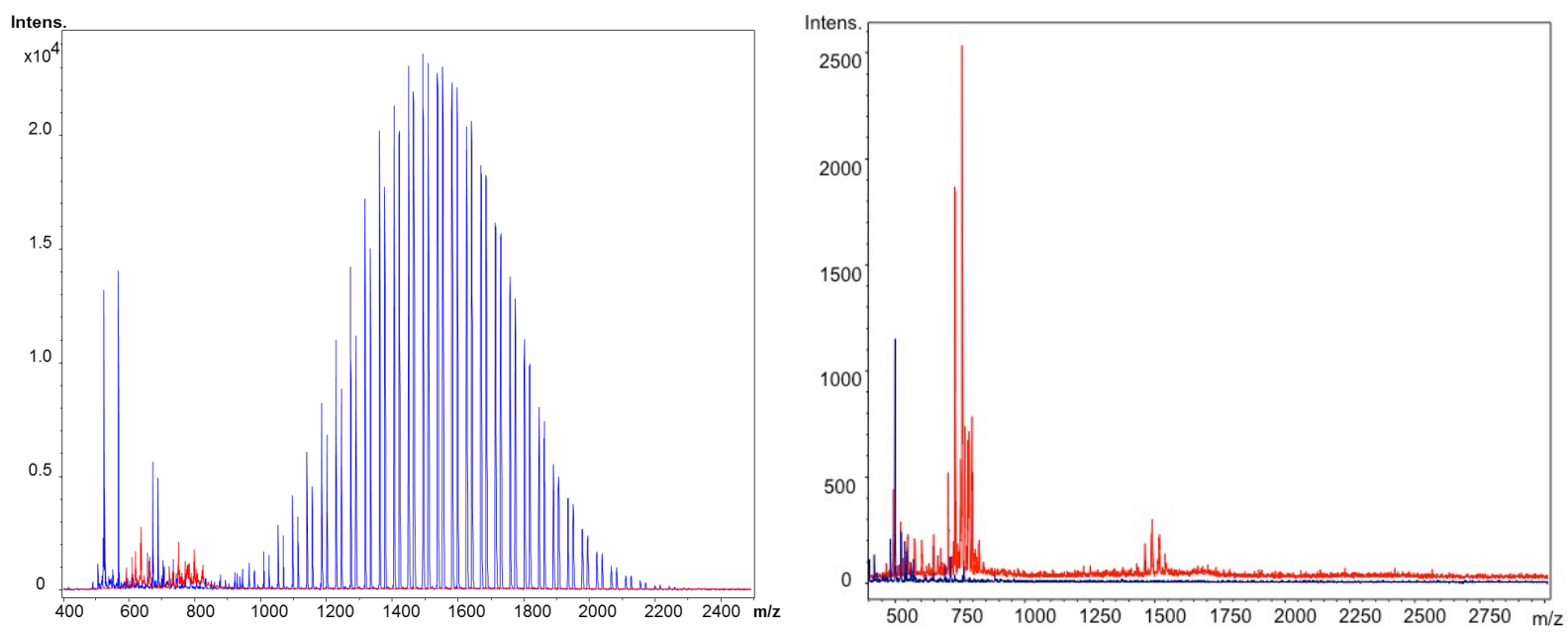

S2. Interferences of embedding materials on fly brain spectra. A. Spectral overlay for OCT embedding media (blue) and fly brain using DHB sublimation (red). The very high peak cluster of OCT covers the mass range from 900 to $2200 \mathrm{Da}$. In the lower mass range, OCT peaks also partially overlap with peaks from the fly brain. B. Spectral overlay for gelatin (blue) and fly brain using DHB sublimation (red).

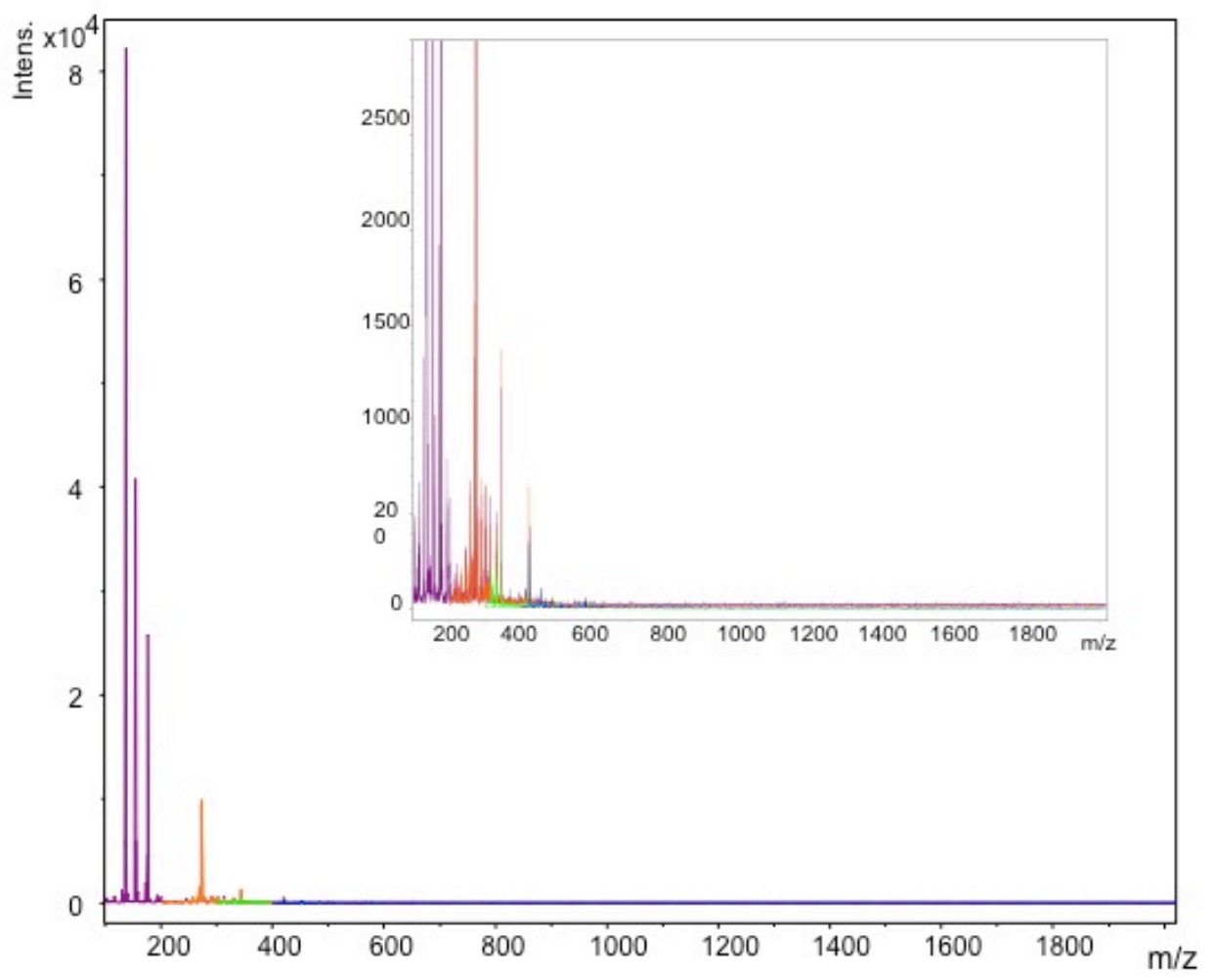

S3. Spectral interference of DHB at mass range below $400 \mathrm{Da}$. Spectra of DHB at mass range 400$2000 \mathrm{Da}$ (blue); 300-2000 Da (green), 200-2000 (red), 100-2000 (purple). Very high peaks of DHB are observed from the mass lower than $300 \mathrm{Da}$. 


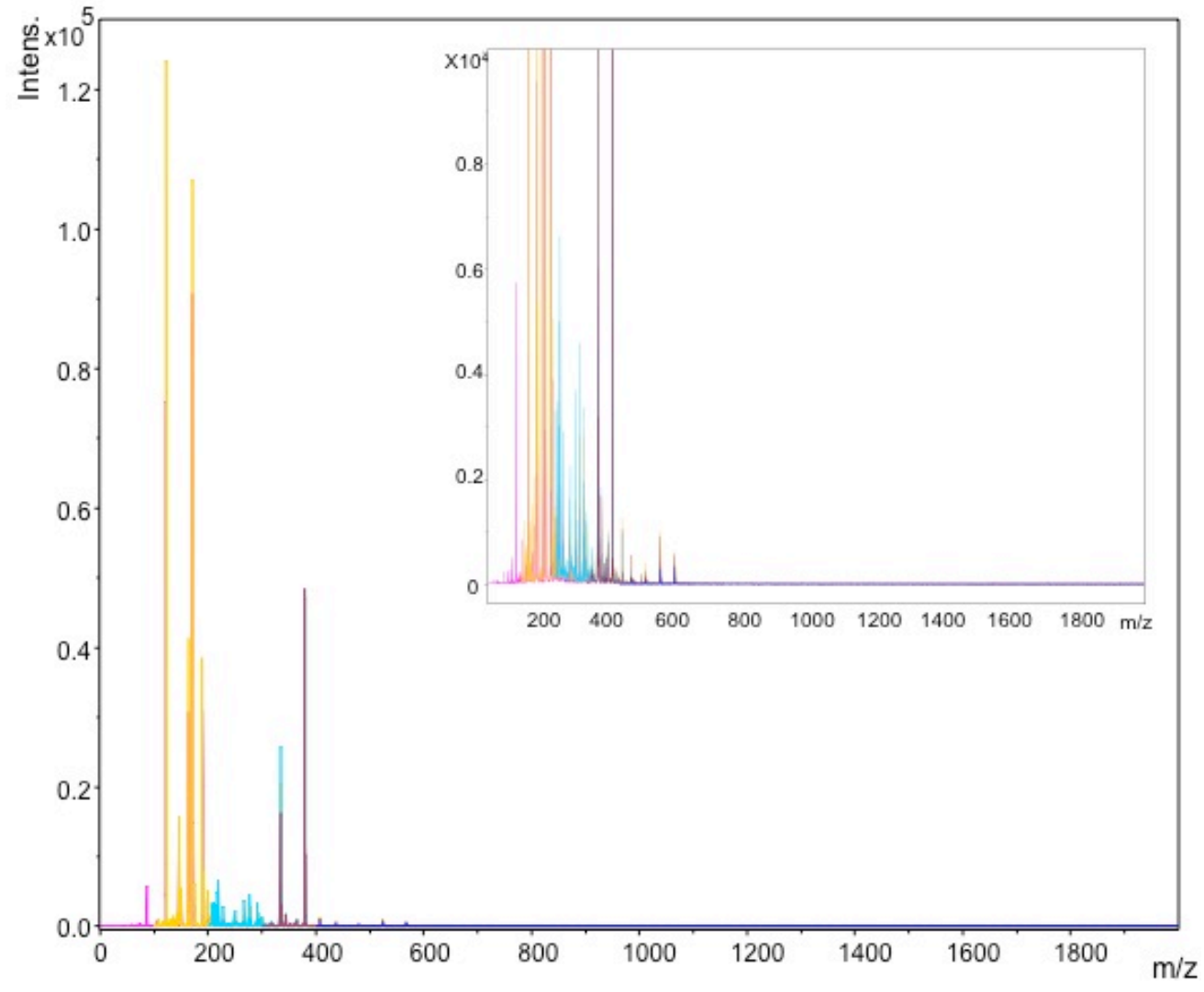

S4. Spectral interference of CHCA at mass range below 400Da. Spectra of DHB at mass range 4002000 Da (dark blue); 300-2000 Da (dark red), 200-2000 (light blue), 100-2000 (orange), and 0-2000 (pink). 

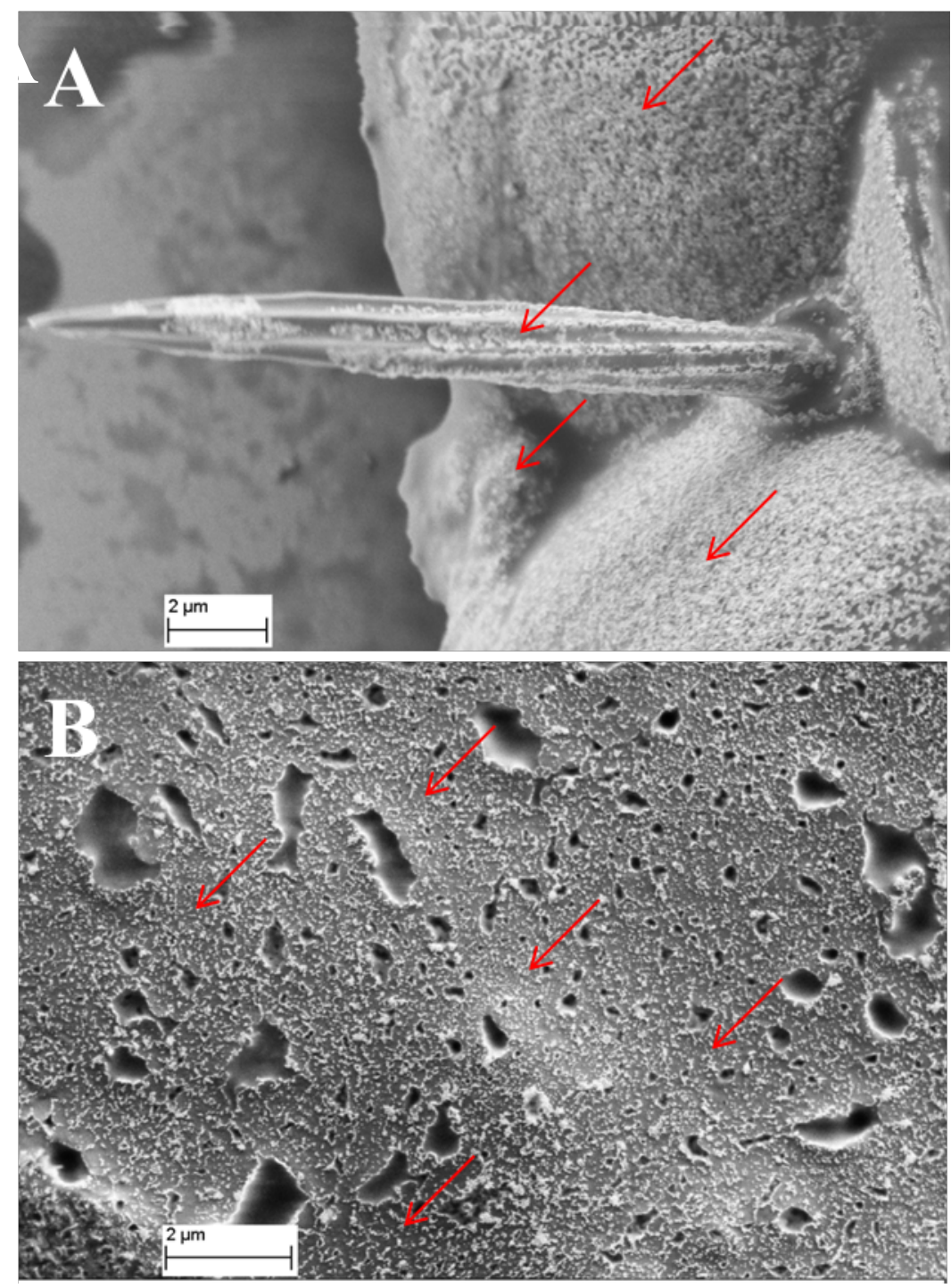

S5. SEM images show distribution of AuNPs on the surface of the fly brain. A: AuNPs cover the eye; B: AuNPs distribute homogeneously on the surface of central brain. Arrows show some nanoparticles on the sample surface. 


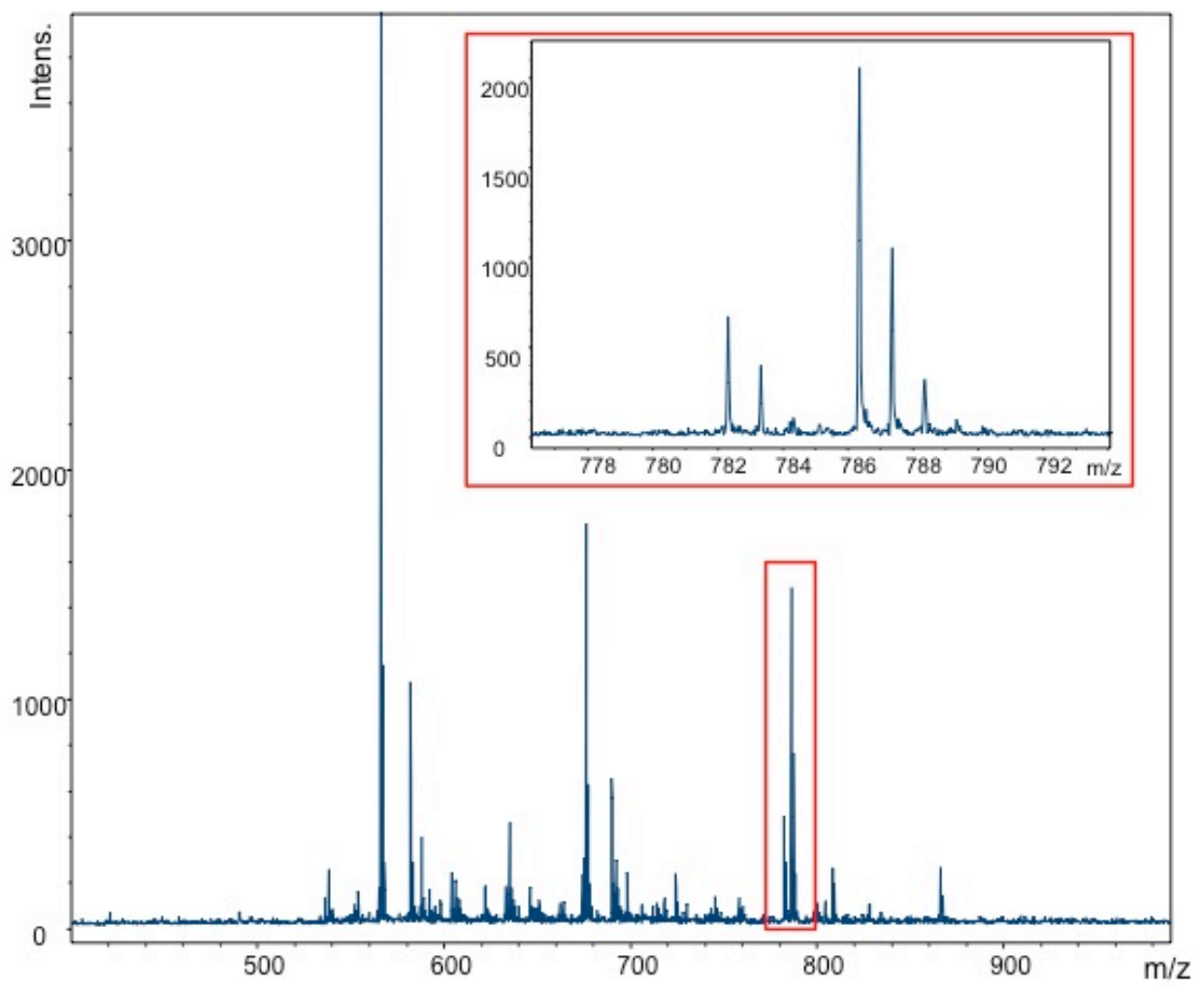

S6. Standard lipid analysed with DHB matrix, DLPC $100 \mu \mathrm{g} / \mathrm{mL}$ at $\mathrm{m} / \mathrm{z} 782.4$ and DOPC 250 $\mu \mathrm{g} / \mathrm{mL}$ at $\mathrm{m} / \mathrm{z} 786.5$.

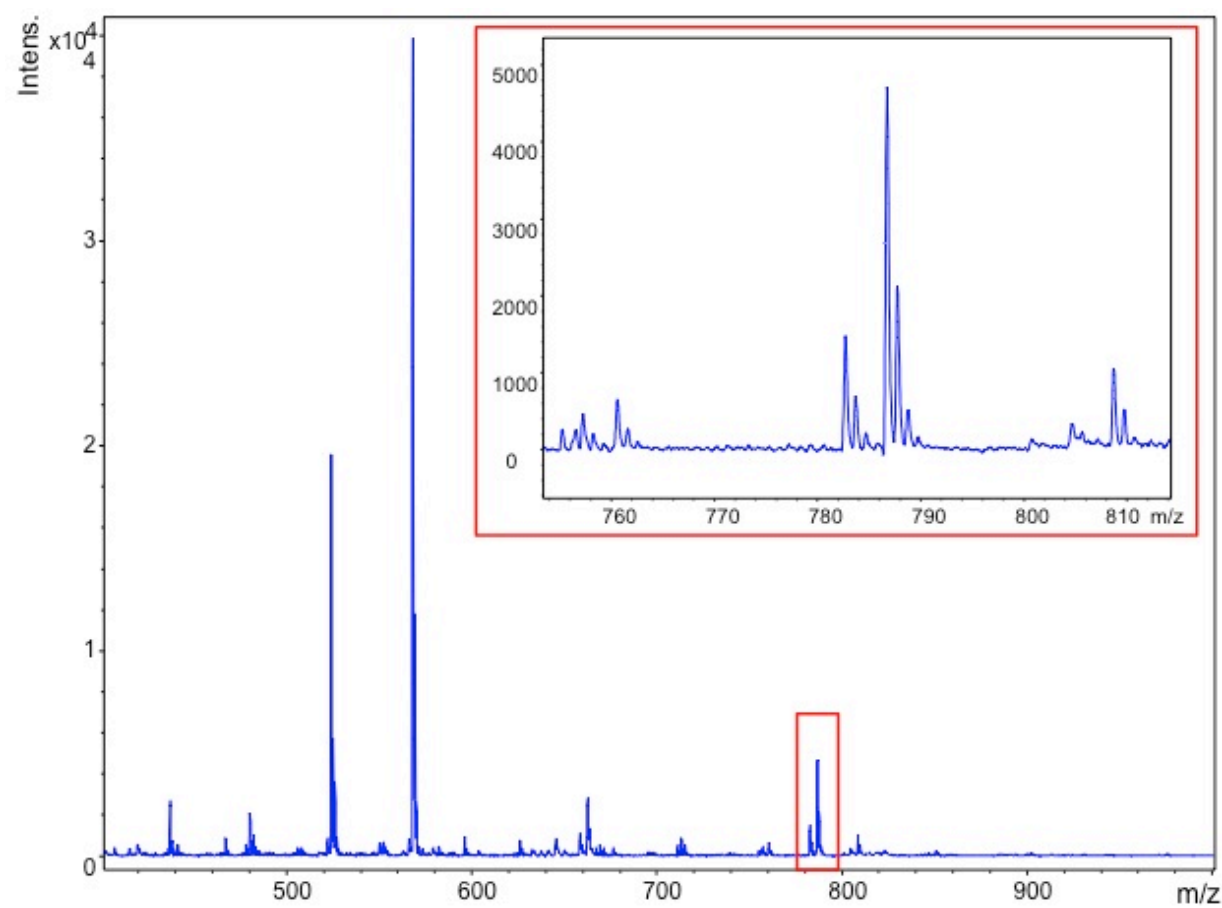

S7. Standard lipid analysed with CHCA matrix, DLPC $100 \mu \mathrm{g} / \mathrm{mL}$ at $\mathrm{m} / \mathrm{z} 782.4$ and DOPC 250 $\mu \mathrm{g} / \mathrm{mL}$ at $\mathrm{m} / \mathrm{z} 786.5$. 


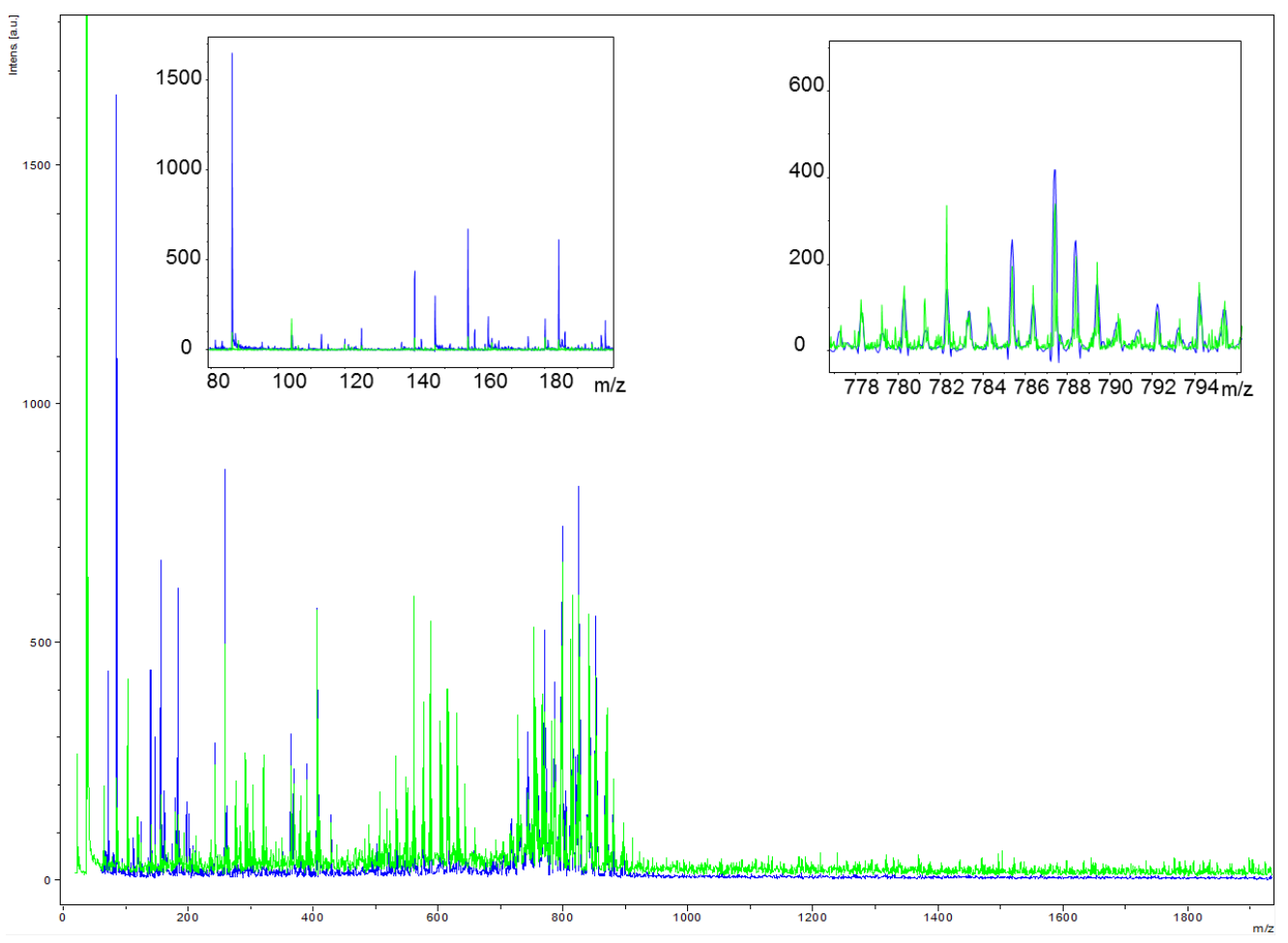

S8. Spectra of standard lipids on fly brain sample matrix analyzed with AuNPs. DLPC $100 \mu \mathrm{g} / \mathrm{mL}$ at $\mathrm{m} / \mathrm{z} 782.4$ and DOPC $250 \mu \mathrm{g} / \mathrm{mL}$ at $\mathrm{m} / \mathrm{z} 786.5$. Molecular peaks of DLPC and DOPC are not observed whereas the fragment ions $\mathrm{m} / \mathrm{z} 86.1$ and 184.1 present at high intensity. Fly brain (green), fly brain spiked with standard lipids (blue). 


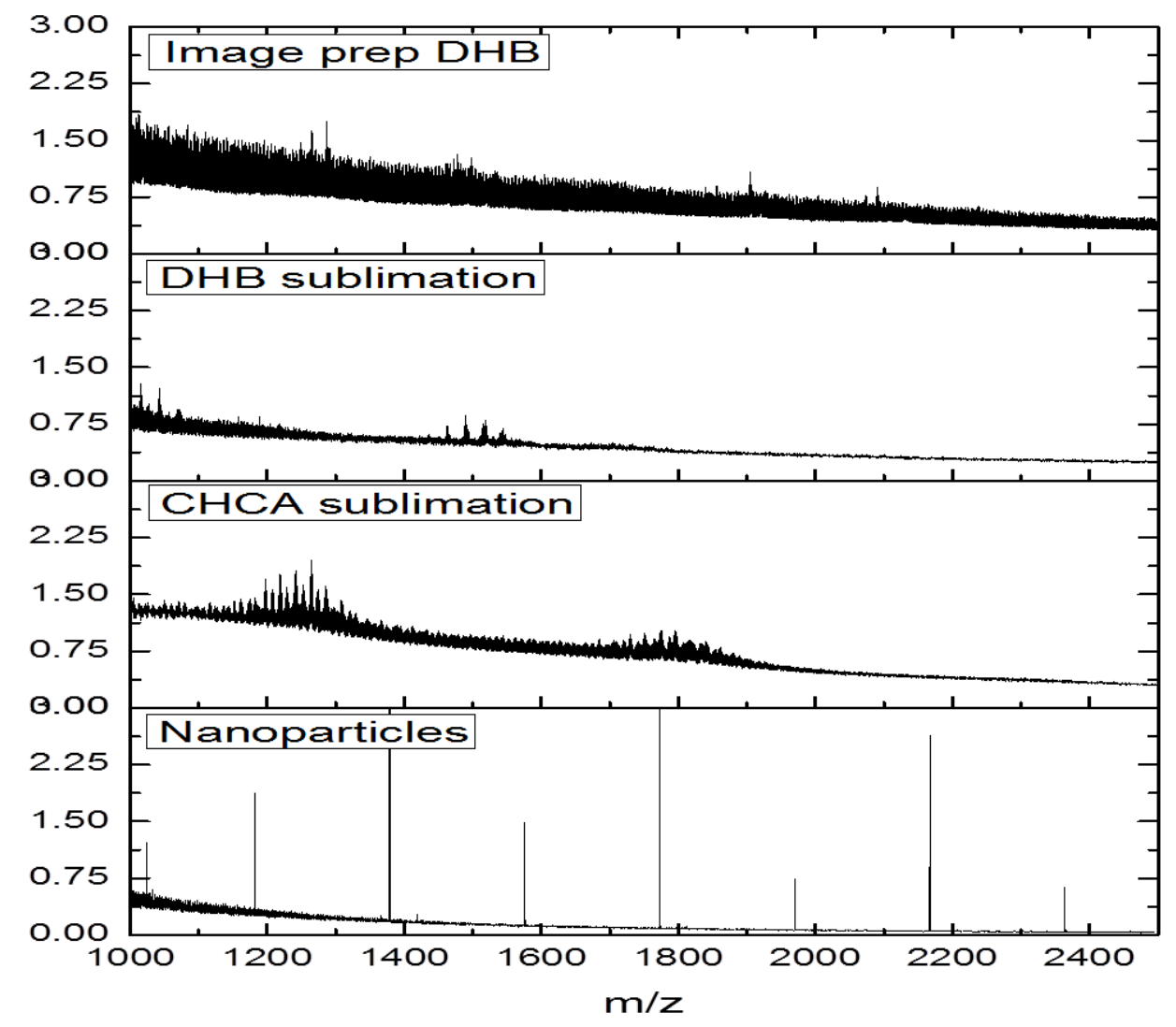

S9. Comparison of MALDI and SALDI spectra for fly brains obtained from different sample preparation methods in positive mode, Image Prep automatic spraying with DHB, sublimation with DHB followed by recrystallization with TFA, sublimation with CHCA, and modification with AuNPs. Mass range 1000-2500. 
Table S1. Peaks with enhanced signal intensities on the fly brain sublimated with DHB and treated with TFA compared to the brain only sublimated with DHB.

\begin{tabular}{|c|c|}
\hline $\mathbf{m} / \mathbf{z}$ & Peak assignment \\
\hline 438.5 & Unknown \\
440.6 & Unknown \\
552.4 & Unknown \\
554.6 & Unknown \\
556.6 & Unknown \\
726.5 & $\mathrm{PC}(32: 4) \mathrm{C}_{40} \mathrm{H}_{73} \mathrm{NO}_{8} \mathrm{P}^{+}$ \\
730.5 & $\mathrm{PC}(32: 2) \mathrm{C}_{40} \mathrm{H}_{77} \mathrm{NO}_{8} \mathrm{P}^{+}$ \\
732.6 & $\mathrm{PC}(32: 1) \mathrm{C}_{40} \mathrm{H}_{79} \mathrm{NO}_{8} \mathrm{P}^{+}$ \\
758.6 & $\mathrm{PC}(34: 2) \mathrm{C}_{42} \mathrm{H}_{81} \mathrm{NO}_{8} \mathrm{P}^{+}$ \\
760.6 & $\mathrm{PC}(34: 1) \mathrm{C}_{42} \mathrm{H}_{83} \mathrm{NO}_{8} \mathrm{P}^{+}$ \\
768.5 & $\mathrm{PE}(38: 4) \mathrm{C}_{43} \mathrm{H}_{79} \mathrm{NO}_{8} \mathrm{P}^{+}$ \\
770.6 & $\mathrm{PE}(38: 3) \mathrm{C}_{43} \mathrm{H}_{81} \mathrm{NO}_{8} \mathrm{P}^{+}$ \\
796.6 & {$[\mathrm{PC}(34: 2)+\mathrm{K}]+\mathrm{C}_{42} \mathrm{H}_{80} \mathrm{NO}_{8} \mathrm{PK}^{+}$} \\
798.7 & {$[\mathrm{PC}(34: 1)+\mathrm{K}]+\mathrm{C}_{42} \mathrm{H}_{82} \mathrm{NO}_{8} \mathrm{PK}^{+}$} \\
\hline
\end{tabular}

